\title{
Neurodoping in Chess to Enhance Mental Stamina
}

\section{Introduction}

This article will discuss substances/techniques that target the brain in order to enhance sports performance (known as "neurodoping"). It will consider whether neurodoping in mind sports, such as chess, is unethical and whether it should be a crime. Rather than focusing on widely discussed objections against doping based on harm/risk to health, this article will focus specifically on the objection that neurodoping, even if safe, would undermine the "spirit of sport". This topic deserves attention, given that a) relatively safe methods of performance enhancement are increasingly being explored in the context of chess [14],[1]) the World Anti-Doping Agency (WADA) currently prohibits performance enhancement if it undermines the spirit of sport, even if it is not dangerous to health; and c) doping (even if safe) seems to fit the current definition of fraud in England and Wales, ${ }^{1}$ in certain circumstances, and some academics have argued that non-harmful doping should be prosecuted as fraud.

The article will have the following structure. Firstly, it will briefly explain why chess can be considered a sport, since classifying chess in this way is a relatively recent development, at least in Western Europe, and remains somewhat controversial. Secondly, it will outline some possible substances/methods that could be used in order to enhance chess performance and will justify the article's focus on one potential form of neurodoping in particular - "mental stamina enhancement". This type of neurodoping would aim at enabling a competitor's cognitive skills to function at roughly the same level for the duration of a chess tournament, reducing the extent to which the competitor's performance declines with fatigue. Thirdly, this article will cast doubt on arguments that mental stamina enhancement would be unethical and contrary to the spirit of sport (as defined by WADA). It will focus on the following aspects of the spirit of sport: dedication and commitment, naturalness and fair play. This article will stress the importance of distinguishing the ethical argument that doping violates the "spirit of sport" from the definitional objection that once doping becomes routine in a certain "sport", it would not count as a sport anymore. The fourth section will discuss the definitional objection and will argue that mental stamina enhancement in chess might disqualify chess from being a "sport" (according to traditional, rather than revisionist definitions of sport). Yet it will argue that this definitional objection does not provide strong enough grounds to justify criminalising non-harmful neurodoping. The fifth section of the article will respond to a recent proposal to treat doping as a criminal offence and will argue that criminalising non-harmful neurodoping would be disproportionate.

\section{Chess as a Sport}

The question of whether chess is a sport has important implications for chess in terms of funding and publicity, and whether chess should be included in potential criminal legislation surrounding sports doping (see Chess, Mental Stamina and the Definition of Sport, below). For the purpose of this article, it is important to consider whether there is a prima facie case for classifying chess as a sport, in order to justify the article's discussion of whether neurodoping in chess would undermine the spirit of sport or cause chess to cease to be a sport.

There has been growing support for the idea that chess is a sport, but this classification still remains somewhat controversial. The World Chess Federation, known as FIDE (Fédération Internationale des Échecs) is a member of the International Olympic Committee (IOC). The IOC recognised chess as a sport in 1999, although, so far, chess has not been included on the Olympic programme. Chess was, however, included in the 2006 and 2010 Asian Games. In Russia and Eastern Europe, chess has been recognised as a sport for decades. For example, Kobeila [2] notes that, in these countries, chess events are reported as part of the "sports news" on television, chess players appear on sports magazine covers, and chess clubs are often subdivisions of sports clubs. In the USSR chess players were regularly awarded the "Soviet Hero of Sport" award. Participating in professional chess has significant physiological effects on the body and requires a high level of physical fitness. A player competing in a major tournament, such as the World Cup of Chess, can burn up to 6,000 calories a day purely as the result of stress and mental activity and chess grandmasters during competitions can experience physiological changes such as increased blood pressure at levels comparable to competitors in athletic sports ([3],[4]: 419-420, [5]). There is evidence that physical exercise and nutrition are crucial for

\footnotetext{
${ }^{1}$ Fraud Act 2006, S.2 (1) (see fn18 below).
} 
sustaining the cognitive abilities and mental energy required for success in competitive chess. These cognitive functions are affected by cardio-respiratory health and the brain's ability to derive energy from glycogen, which can be enhanced by regular physical exercise and possibly by a carbohydrate rich diet [6]. When preparing for tournaments, chess grandmasters follow demanding exercise regimes and strict diets, similar to the diets and training that athletes undertake before athletic events (for studies on the effect of diet and exercise on chess performance see $[7,8]$ ).

\section{Neurodoping and Mental Stamina}

Rules against doping in chess are quite recent and have been opposed by many elite players, who consider anti-doping tests unnecessary, insulting and/or intrusive ([9]: 115-116). Nevertheless, these rules have been enforced. For example, Vassily Ivanchuk was controversially deemed to have committed doping by officials when he refused to take a drug test at the 2008 Chess Olympiad, although he was cleared [10]. Substances on WADA's prohibited list that are most relevant to chess include: amphetamines (e.g. Adderall, Ritalin), ephedrine and methylephedrine, pseudoephedrine and modafinil $[11,12] .{ }^{2}$ Substances that are not on WADA's prohibited list, but which are included on the monitoring programme are: caffeine ${ }^{3}$ and codeine [11]. FIDE's handbook highlights modafinil, Adderall and Ritalin, in particular, as forms of "psychopharmacological cognitive enhancement" with the potential illicitly to improve chess performance [12]. Ritalin and Adderall are stimulants which are widely prescribed for the treatment of attention deficit hyperactivity disorder (ADHD), especially in children. Modafinil is prescribed for narcolepsy, excessive daytime sleepiness and shift work sleep disorder. There is evidence that healthy individuals, such as university students, are increasingly using these drugs in an attempt to improve cognitive abilities, e.g. working memory and attention [13]. ${ }^{4}$ Current evidence suggests that using these drugs for the purpose of cognitive enhancement may be relatively safe..$^{5}$ According to Mihailov and Savulescu ([9]: 124), Ritalin and Modafinil are "no more dangerous than caffeine". Some researchers have also discussed the potential for transcranial direct current stimulation (tDCS) to improve chess performance (tDCS is not currently on WADA's prohibited list) [14]. TDCS involves placing electrodes outside the skull in order to transmit a weak direct current to the primary motor cortex. The scientific consensus so far is that tDCS poses no major health risks [14]. However, it should be noted that we do not yet have long-term studies of the safety of novel drugs/techniques aimed at cognitive enhancement [14].

There are ongoing debates about whether the prohibited interventions are effective. Mihailov and Savulescu are sceptical about whether cognitive enhancement interventions could make professional chess players more skilful at their game [9]. Even if these interventions could improve performance on psychometric tests of cognitive functions, e.g. working memory, this is likely to be of limited relevance. Such cognitive functions, or even variations in general intelligence, seem not to make the difference between weaker and stronger professional chess players. Skill at professional chess seems to depend more on domain-specific expertise (complex abilities, that result from extensive experience of the particular activity, rather than general, transferable skills) ([9]: 121-123).

If this is correct, then the prospect that an intervention might be developed to enhance mental stamina could be more realistic than the idea of a drug to enhance chess skill or creativity. Success in chess competitions depends partly on maintaining one's cognitive skills at a high level throughout stressful and lengthy tournaments. Although everyone's cognitive abilities decline with fatigue, there are individual differences (and possibly gender differences [15]) in mental stamina. Traditional interventions like diet and exercise, mentioned above, enable professional chess players to have aboveaverage mental stamina. However, despite rigorous training and a nutritious diet, there will still be variations in mental stamina among professional chess players, due to natural variations in factors such as glycogen storage and metabolism [15]. This may mean that some professional chess players, despite perhaps reaching higher peaks of skill and creativity than their competitors, are hampered by having less stamina than other contestants. An intervention to enhance mental stamina would not improve a

\footnotetext{
${ }^{2}$ Some of these substances are only banned/monitored when their concentration in urine is over a certain level.

${ }^{3}$ It is monitored when its concentration is over $12 \mathrm{mcg}$ per $\mathrm{ml}$.

${ }^{4}$ Possession and supply of controlled substances outside a medical context are illegal (see the Misuse of Drugs Act 1971 and the Medicines Act 1968, for discussion see [13]) and is explicitly banned by some university codes of conduct.

${ }^{5}$ Although side effects are possible, and more research is needed on long-term effects.
} 
recipient's peak cognitive performance, but it could still be classed as cognitive enhancement, because it would aim to enable participants to maintain peak cognitive performance for longer. This article will not discuss extending mental stamina beyond what is currently possible for those with most mental stamina. Instead, it will discuss improving the mental stamina of chess players who are at the lower end of the mental stamina spectrum compared with other elite chess players, while being above average in mental stamina compared with the general population (hence the intervention would still be an enhancement, rather than a treatment). ${ }^{6}$

Some of the cognitive enhancement interventions mentioned above might have the potential to enhance mental stamina. For example, tDCS may improve endurance and reduce feelings of fatigue [14]. Caffeine and modafinil can increase alertness [9]. There is some evidence that modafinil is more effective at restoring the performance of fatigued recipients, rather than improving the performance of those who are not fatigued ([6], [9]). However, this article does not aim to argue that there are mental stamina enhancements currently available that could significantly improve professional chess performance. Rather, it will discuss the philosophical and legal implications of mental stamina enhancements that might be developed in the future. These interventions might be less vulnerable, compared to other forms of performance enhancement, to certain arguments for regarding performance enhancement as unethical or even worthy of criminalisation. Therefore, these interventions are of philosophical and legal interest. This article will not discuss objections to doping based on harm/risk to health because these objections have been widely discussed elsewhere [16] and because some of the interventions mentioned above, which may have the potential to enhance mental stamina, seem relatively safe. In this article the phrase "nonharmful doping" will sometimes be used to refer to performance enhancement interventions that do not carry significant health risks to recipients of the intervention, if taken in normal doses. ${ }^{7}$ This phrase is not meant to rule out the possibility that such doping might cause harm in a broader sense (e.g. harm to the sport), which will be discussed further below.

\section{Chess, Mental Stamina and the Spirit of Sport}

WADA prohibits any substance or technique that satisfies two out of the following three criteria: a) it enhances or has the potential to enhance sporting performance; $b$ ) it risks or has the potential to risk the athlete's health; or c) it violates the "spirit of sport" [17]. Thus, a performance enhancing substance that poses no risk to health may be banned on the basis that it violates the spirit of sport. WADA also invokes the spirit of sport to justify a tough approach to doping including 1) harsh sanctions, such as financial penalties, a 4-year suspension for a first offence and a lifelong suspension for repeated offences; 2) strict liability (i.e. the absence of a fault requirement such as recklessness or intention); 3) vicarious liability (i.e. holding the team responsible for the actions of an individual); and 4) a relatively low standard of proof for doping offences - comfortable satisfaction, rather than beyond reasonable doubt [17]. The concept of the spirit of sport deserves further discussion, as it plays a crucial role in WADA's justification of an aggressive (and, some have argued, disproportionate [18]) anti-doping policy and it has also featured in arguments for the criminalisation of doping (discussed in "The Criminalisation of Neurodoping in Chess", below). WADA describes the spirit of sport in the following terms:

"Anti-doping programs seek to preserve what is intrinsically valuable about sport. This
intrinsic value is often referred to as 'the spirit of sport.' It is the essence of Olympism, the
pursuit of human excellence through the dedicated perfection of each person's natural talents.
It is how we play true. The spirit of sport is the celebration of the human spirit, body and mind,
and is reflected in values we find in and through sport, including. Ethics, fair play and honesty;
Health; Excellence in performance; Character and education; Fun and joy; Teamwork;
Dedication and commitment; Respect for rules and laws; Respect for self and other

\footnotetext{
${ }^{6}$ Limiting mental stamina enhancement to competitors at the lower end of the spectrum (relative to other competitors) is one way of responding to the objection that biological enhancements involve an undesirable endless pursuit of perfection (see [32]). A detailed critique of this objection is outside the scope of this article. For further discussion see, e.g. [35].

${ }^{7}$ Their safety might be compared to substances such as caffeine[9:124], which are generally regarded as safe, but can be dangerous in high doses.
} 


\section{participants; Courage; and Community and solidarity. Doping is fundamentally contrary to} the spirit of sport" [17].

It should be noted that some aspects of this description - specifically "honesty" and "respect for rules and laws"- could not logically be invoked in order to justify a ban on performance enhancement, as they depend on the prior existence of such a ban, i.e. if performance enhancement were not prohibited, its use would not be dishonest or disrespectful of rules or laws [19]. WADA's description of the spirit of sport has also been criticised for being too "vague" ([20],[21], [22]) and the many concepts within this description could be fleshed out in a variety of ways. It is beyond the scope of this article to discuss all aspects or interpretations of the spirit of sport. This article will focus on "dedication and commitment", "fair play" and "naturalness".

This article will interpret WADA's claim that doping is "fundamentally contrary to the spirit of sport" as being an ethical objection to doping [23]. Although "ethics" is listed as one aspect of the spirit of sport, most of the other aspects also seem to have an ethical dimension. This interpretation also fits with WADA's support for severe sanctions for doping in the knowledge that those caught doping are typically condemned or stigmatised. It is important to distinguish the ethical argument that doping violates the "spirit of sport" from the definitional argument that once doping becomes routine in a certain "sport", it would not count as a sport anymore. for example, John Gleaves seems to be making a definitional argument when he writes: "a golfer who "resorts to means other than ... strokes to try to accomplish this end, by virtue of using these alternative means, is prevented from accomplishing it which is just another way of saying that one is no longer playing golf' (Morgan 2008, 136). The same is true for athletes using performance-enhancing drugs to accomplish an end with no regard for the means." [28:279]. The definitional argument, by itself, does not necessarily imply that doping should be banned (let alone criminalised). The definitional argument, by itself, does not establish that an activity would be less valuable just because it ceased to be a "sport". ${ }^{8}$ After ceasing to be a sport, the activity might have equal or greater value. I will argue that, if there are no persuasive ethical objections against a certain form of doping, the definitional argument does not provide sufficient grounds to justify criminalising doping. The current section will focus on ethical arguments. The definitional argument will be discussed separately in a later section.

Dedication and Commitment

Dedication and commitment are typically shown in sport through exerting effort and persevering despite obstacles. Effort and perseverance are typically regarded as morally valuable. They are transferable skills that can be used to benefit society in many ways; effort and perseverance intuitively seem to be under the individual's control ([24], but see [25]) to some extent, arguably making them apt targets for praise; and celebrating/praising effort and perseverance can encourage people to successfully complete projects that benefit society. ${ }^{9}$ If the routine use of mental stamina enhancement in chess provided a "quick fix" allowing chess players to avoid arduous training, this might seem ethically problematic for the following reasons. Firstly, if the "quick fix" became so popular that traditional, more effortful chess disappeared, this change might deprive wider society of an activity that promoted the important moral values of effort and perseverance. Secondly, the routine use of such "quick fixes" might deprive professional chess players of opportunities to develop the moral virtue of effortful perseverance within the context of their sport. Given that professional chess players devote such a large proportion of their time to playing chess, undermining the (supposed) ability of the game to promote moral character development, might be a significant loss.

\footnotetext{
${ }^{8}$ In addition to making the definitional point, Gleaves also argues that doping could undermine features that make sport (as currently practiced) valuable. However, it could be objected that Gleaves' argument does not rule out the possibility that doped "sport" might be equally (or more) valuable, just in a different way. For a similar objection see [29:172]

${ }^{9}$ Philosophers disagree about the meaning of "control" and the extent to which people have control over how much they persevere (compare, e.g., [24] and [25]). The tendency to persevere is arguably subject to forces beyond the individual's control, e.g. genetic and environmental factors. This might undermine the argument that it is intrinsically good to praise people for persevering in valuable activities, purely because they deserve praise. However, these considerations do not undermine the instrumental value of celebrating perseverance. It would still be worthwhile to praise persevering in valuable activities, because there is evidence that praising perseverance can encourage it.
} 
However, in response to both of the above-mentioned concerns, it is unlikely that mental stamina enhancement interventions (e.g. drugs or tDCS) could replace the need for effort and perseverance. In order to gain the domain-specific expertise required to be an elite chess player there is no substitute for years of practice. Nor is it realistic to suppose that the degree of physical fitness required for gruelling tournaments could be achieved through drugs or tDCS alone, without the need for arduous exercise regimes. Rather, neurointerventions could enable professional chess players to practice for longer, thereby leading to more effort and perseverance overall.

Furthermore, effort (in the sense of an aversive psychological experience) is not the only way in which dedication and commitment can be demonstrated. In fact, Maslen et al [26] have persuasively argued that sometimes choosing a less effortful route to achieve a goal can demonstrate more commitment than exerting greater effort. They give the example of pre-commitment contracts - putting in place external aids to combat weakness of will and to increase the chance of completing a task successfully. For instance, one could remove temptations or distractions from one's environment, or create a training/study timetable [26]. These strategies can make a task more absorbing and enjoyable and reduce the amount of subjective effort required to complete it (reducing the need to struggle to maintain focus or resist temptation). Devising such strategies to achieve a goal efficiently can show commitment to that goal, as well as displaying the virtues of self-knowledge and awareness of one's limitations [26]. Whereas incurring a greater risk of failure, by choosing a more effortful route might show less commitment to the goal [26]. Furthermore, exerting effort is not the only "cost" that can demonstrate dedication and commitment. Other relevant costs include sacrificing time and opportunities engage in other pursuits [26]. Thus, a competitor who chooses to take mental stamina enhancement might demonstrate dedication and commitment through 1) applying herself to devising efficient strategies to excel at professional chess; 2) taking time to acquire self-knowledge of her relevant limitations; 3 ) enabling more time to be spent training, while sacrificing opportunities to engage in other activities or forms of relaxation.

In the context of most real-life ethical decision-making, it is not more virtuous to introduce unnecessary/artificial obstacles just so one can exert effort in overcoming them ([26], [27]). For example, someone who rescued a drowning child from a river would not be more virtuous if she tied one arm behind her back in order to make undertaking the rescue more effortful. It might be objected that the point of many sports is to overcome artificial obstacles (i.e. excelling within the artificial constraints of the rules of the game). However, if embodying and encouraging moral virtues is meant to be an important part of the spirit of sport, it would be preferable to focus less on overcoming artificial or avoidable obstacles and to focus more on tackling challenges that are inherent in worthwhile activities. Mental stamina enhancements could allow chess players to focus more on the problemsolving challenges inherent in chess, rather than battling avoidable fatigue.

It might be objected that willingness to engage in performance enhancement can sometimes demonstrate a greedy, cynical obsession with winning or with external incentives (such as prize money and fame), rather than showing dedication and commitment to the internal values of the sport ([28]; [29]). In reply, a chess player who takes mental stamina enhancement may be motivated by a desire to spend more time developing skills such as creativity and strategic thinking, which are valuable for their own sake, and which seem more central to the purpose of chess than mental stamina is. It seems plausible that the value of chess lies primarily in the intellectual and creative skills of the players - their ability to work out what moves will enable them to win and to develop winning strategies that are original or seem "elegant". In contrast, the value of running a marathon is more closely connected with stamina and a marathon runner who took a physical stamina enhancement might be accused of missing/undermining the point of marathons or being motivated by extrinsic incentives. Arguably, what makes chess valuable is more comparable to what makes art worthwhile, than to what makes running marathons valuable (for a discussion of chess as an art form, or of the aesthetic aspects of chess see, e.g., [30]). ${ }^{10}$ If so, using neurointerventions to enhance mental stamina would not seem to undermine or

\footnotetext{
${ }^{10}$ This article suggests that endurance is less central to the value of chess, than to the value of marathons. However, this is not to deny that endurance is significant when it comes to deciding whether or not to classify chess as falling within the definition of "sport" - see Chess, Mental Stamina and the Definition of Sport,
} below. If chess required less endurance, because players were permitted to take mental stamina enhancements, 
to show a lack of commitment to the value of chess. The value of a work of art, such as a painting, does not seem to depend on how the artist got the energy to create it. It might be objected that chess is less like painting, and more similar to a performing art, such as ballet and that part of the value of ballet is the athletic ability of the dancers to keep dancing apparently effortlessly long after most people would have become exhausted. However, that hardly seems central to the value of ballet. A ballet critic who said of a dancer's performance "it's amazing how she can keep going for so long!" would seem to be damning her with faint praise (like saying of an actor "it's amazing how he can remember all those lines!"). One would not put these quotes on posters advertising the performance. Similarly, the ability to keep playing for a long time without becoming fatigued does not seem central to the value of chess. Thus, taking mental stamina enhancement would not demonstrate a lack of dedication or commitment to the central purpose of chess.

Fair Play and Naturalness

Proponents of performance enhancement have often highlighted the unequal distribution of abilities arising from the natural lottery, arguing that it is unfair to deny individuals the means of remedying biological bad luck, if safe and effective performance enhancement were available [31]. However, opponents of performance enhancement frequently reply that part of the purpose of sport is to showcase people's natural talents (e.g. [17], [23] and [32]. It is debatable whether naturalness should continue to be part of the "spirit of sport" (as a moral concept), given the controversy over whether naturalness is of ethical value [33]. There is not scope within this article to resolve that issue. Instead, this article will suggest that in the specific context of mental stamina enhancement in chess fairness-based considerations may sometimes support permitting such interventions, and unnaturalness objections seem less worrying in this context.

Interventions that are not "natural" have sometimes (controversially) been allowed in athletic sports, if the intervention is designed to repair a disadvantage, rather than being designed to enhance the athlete's abilities. For example, Oscar Pistorius was eventually permitted to compete alongside able-bodied athletes, after an initial ruling that his artificial legs gave him an unfair advantage was overturned [34]. Some theorists have distinguished between interventions that provide "the very means to compete" (which may be ethically permissible) and "enhancing what is already nearly perfect" (which is arguably ethically problematic) ([34]: 241). Sandel has argued that there is value in appreciating the "given", rather than endlessly striving for perfection [32] (for a reply to Sandel, see [35]). ${ }^{11}$

If mental stamina enhancement could be reserved only for competitors who were already at the lower end of the mental stamina spectrum vis-à-vis other elite chess players, this would prevent an endless pursuit of perfection. Rather, it could provide chess players who had high levels of creativity and strategic skills with the "very means to compete" against those who were similarly or less gifted in terms of creativity and strategy, but who had much greater stamina. Furthermore, the objection that the purpose of sport is to showcase natural talents seems less problematic in the context of enhancing mental stamina in chess. This is because, as argued above, creativity and strategy seem more central to the purpose of chess than mental stamina. Providing certain chess players with mental stamina enhancement could release their natural potential to display talents that are central to the purpose of chess - talents for strategic thinking and creativity - whereas the "unnaturalness" of the enhancement would only affect an ability that is less central to the purpose of chess - mental stamina.

It might be objected that, intuitively, fairness seems to require some correlation between hard work and success [29] and that mental stamina enhancement could place some of the most deserving competitors

this would not significantly undermine the value of chess, but it would make it harder to categorise chess as a sport.

${ }^{11}$ Sandel warns against "hyperagency" - the desire to have excessive/complete control over our own nature, rather than viewing natural talents as a gift, partly outside the agent's control. He claims that hyperagency could undermine a valuable sense of humility, could burden us with an overwhelming sense that we are responsible for all our attributes, and could undermine solidarity by causing us to blame others for failing to take control over all their attributes [32]. Hyperagency seems to be a matter of degree. Even if Sandel is right that hyperagency is problematic, it is hard to tell at what point the desire to control our nature becomes excessive. Restricting interventions to competitors at the lower end of the spectrum of a certain ability, e.g. mental stamina, (relative to other competitors) might be one way of drawing the line. 
at an unfair disadvantage by reducing the contribution that hard work makes to success in professional chess. It might be feared that chess players who, due to hard work, once (deservedly) had an advantage over other competitors, could be disadvantaged compared to chess players who worked less hard but who took mental stamina enhancements. However, this problem could be mitigated by monitoring competitors' training regimes and only allowing competitors to take neuroenhancements if they have already undertaken a certain level of physical training. This might encourage more hard work overall if the authorities set the required amount of training at a high level. Another possibility would be to match opponents with similar levels of stamina (similar to weight classifications in boxing, see also [36]), regardless of whether they achieved that level naturally or artificially. (However, these measures might be difficult to implement in practice.)

To conclude this section: so far, this article has attempted to cast doubt on arguments that permitting mental stamina enhancement in chess would undermine certain key aspects of "the spirit of sport" and would always be unethical. The next section will consider whether chess would no longer satisfy the definition of sport if mental stamina enhancement were permitted.

\section{Chess, Mental Stamina and the Definition of Sport}

Debates about the boundaries of the concept of "sport" are not motivated merely by a desire for "academic tidiness" ([37]: 5). The definition of sport is of practical importance for athletes, sports fans, investors and researchers. Classifying an activity as a sport has implications for taxation law, ${ }^{12}$ publicity, sponsorship and the training and education of young athletes. As will be discussed later in this article, there have been proposals to criminalise sports doping in the UK and the concept of "sport" appears in the criminal legislation of some jurisdictions that already have such offences. Anyone who wants to research sport needs "an operational definition of the kind of sport he or she intends to research" ([37]: 5 ) and finding a definition that is plausible enough to be endorsed by many researchers will facilitate comparisons between different studies on this topic. The present article will not attempt to defend a particular definition of sport, but rather to demonstrate how, on certain mainstream "traditional" definitions of sport, neurodoping in chess might place chess outside the realm of sport (without necessarily being "contrary to the spirt of sport" in a morally-loaded sense). On the other hand, it will also argue that on a "revisionist" definition of sport (e.g. [2]) neurodoping would not undermine chess's claim to be a sport.

Academics differ about whether chess should currently be categorised as a sport. Parry, taking Olympic sport as a paradigmatic case of sport, formulates a "traditional" definition of sport, i.e. a definition based on how the term has been used historically, rather a revisionist definition that proposes ways of adapting the term in the future [37]. Parry argues that his traditional definition excludes chess. However, this article will argue that chess might, in fact, qualify as a sport according to Parry's definition (or a slightly modified version of this definition), provided that neurodoping (especially mental stamina enhancement) is prohibited. If mental stamina enhancement played a significant role in professional chess, it might cease to qualify as a sport according to traditional definitions.

Parry's methodology when formulating a definition of sport is to analyse how the term "sport" is used by ordinary people who accept "Olympic sport" as a central case of sport, and to try to make explicit what people implicitly mean when they use the term "sport". Parry's definition is as follows: sports (in the sense of Olympic sports) are "institutionalised rule-governed contests of human physical skill" ([37]: 6). According to Parry, chess satisfies all aspects of this definition except the "physical skill" criterion and therefore is not a sport ([37]: 9). In this respect, Parry's definition is similar to the influential account of sport defended by Suits, who denies that chess is a sport for the same reason ([38]: 16). The fact that chess players physically move the pieces is irrelevant, because moving chess pieces does not require "physical skill", is unnecessary (as you could play chess remotely or by proxy), and

\footnotetext{
12 The Value Added Tax Act 1994, Group 10 of Schedule 9 provides for a VAT exemption for certain sports supplies. Chess is currently not included as a sport for the purposes of the VAT exemption. The exclusion of bridge from the VAT exemption for sports has given rise to case law (which upheld the exclusion), e.g. Case C-90/16 The English Bridge Union Limited v Commissioners for Her Majesty's Revenue \& Customs [2017] OJ C 145. However, mind sports, including chess, are included in the definition of amateur sports under the Charities Act 2011, s3(2)(d).
} 
the movement per se is irrelevant to the outcome of the game, i.e. in traditional chess ${ }^{13}$ it is irrelevant how you make the movement - gracefully, quickly etc. Parry distinguishes chess from rifle shooting, which he accepts is a sport although shooting appears to involve minimal physical movement, insisting that "it is false that the required movement involves merely squeezing a trigger. This fails to take into account the total-body control required of a shooter, including balance, stance, rifle hold, controlled breathing, etc., all of which contribute directly to the outcome" ([37]: 9).

In response, it could be argued that the focus on "merely moving chess pieces" is just as misleadingly narrow as the focus on "merely squeezing a trigger". As explained above, chess players must undergo rigorous physical training to facilitate mental endurance in long tournaments, which take a physical toll on the body that is comparable (in terms of elevating blood pressure and burning calories) to sports that are more widely regarded as physical. It might be objected that mental endurance is still a mental skill rather than a physical skill, but this objection could be criticised for relying on an artificial mind-body dualism that fails to take account of the effect of physical training on the mind and the effect of mental activity on the body, as well as the fact that the brain is part of the body. Furthermore, mental endurance seems more analogous to the athleticism involved in paradigm cases of sport, compared with other types of mental activity (e.g. doing crosswords.) Competitors in chess tournaments must maintain intense concentration despite aversive physical symptoms, such as fatigue, restlessness, stiffness etc. and competitors can be left exhausted. Whereas mental activities that do not require endurance (e.g. when you can take a break or have a nap) seem less analogous to traditional sports.

When arguing that chess lacks physical skill, Parry draws an analogy with speed-eating competitions. However, in fact, this analogy could be used to support the claim that chess is a sport, while speedeating is not. According to Parry, "the spirit quails" at the idea that speed-eating meets the "physical and skill elements" of the definition of sport ([37]: 9). Speed-eating may seem "intensely (even disgustingly) "physical", but it "is not a physical movement activity - its primary aim is consumption" ([37]: 9). Further analysis of why speed-eating is not a physical skill (although it probably involves at least as many movements as rifle shooting), might cite the minimal role that control plays in successful speed-eating - success seems largely due to stomach capacity and non-conscious, digestive processes. In contrast, athletic performances typically involve a high degree of conscious control. This only serves to highlight the importance of the mental in paradigmatic cases of sport, strengthening the case for classifying chess as a sport. ${ }^{14}$

It might be objected that blurring the distinction between physical and mental could make the definition of sport too wide. One might worry that even criminal trials within adversarial legal systems could be classed as "sports" (defined as "institutionalised rule-governed contests of human skill") if the requirement of physical skill were weakened so that, for instance, the physicality criterion could be satisfied if advocates did physical training to enhance mental endurance during long trials. In reply, the physicality element is neither sufficient nor necessary to exclude practices such as criminal trials from the definition of sport. The physicality element of the definition of sport is not sufficient to exclude the medieval method of determining guilt through "trial by combat" (which required a high level of physical skill on the part of the combatants). Yet trial by combat was not a sport. It is not necessary to invoke physicality in order to explain why trial by combat or contemporary trials are not sports. Instead, Parry's definition seems to need an additional requirement - that the purpose of sport involves fun or entertainment, or at least that the purpose of sport lies in the activity itself rather than in some independent goal, such as, in the case of criminal trials, the determination of guilt or innocence.

This article has suggested that the mental endurance aspect of professional chess (although not central to the value of chess per se) could be a crucial factor enabling chess to qualify as a "sport" as traditionally defined. However, drug-induced mental endurance might not be enough to qualify chess as a sport. Although it is unlikely that drugs could completely replace the need for physical training, if

\footnotetext{
${ }^{13}$ This can be contrasted with Blitz, which is a form of chess that is played at high speed and involves dexterity - a Blitz expert can make more than 60 moves per minute ([2]: 283).

${ }^{14}$ Furthermore, speed-eating might be distinguished from chess on the grounds that the former does little to promote physical or mental health or wellbeing - ideas which have featured in some legal definitions of sport, e.g. The Charities Act 2011 s3(2)(d) describes sports as activities that "promote health by involving physical or mental skill or exertion". See also Case C 90/16 The English Bridge Union Limited v Commissioners for Her Majesty's Revenue \& Customs [2017], opinion of Advocate General Szpunar, paras 42 and 45.
} 
mental endurance were largely drug-induced, this aspect of chess would likely become less interesting to spectators. If that happened, professional chess would probably still be valued, but due to other factors, such as strategy and creativity. Chess would still be a worthwhile activity, but would look less like a "sport", as sport has traditionally been defined. Definitions can evolve, however. Kobeila cites various examples to illustrate this claim, such as the expansion of the definition of "marriage" to include same sex marriages and the expansion of the term "art" to include "conceptual art" [2]. New sports are constantly being developed and the list of activities that have been classed as sports has changed significantly over time. The suggestion that badminton could be a sport was once "laughable" and badminton is now an Olympic sport ([2]: 292-293). Kobeila argues that with the growth of mind-sports and e-sports the acceptance of a revisionist definition of sport that is broad enough to cover these activities (including chess) is "probable" and also "desirable", because a revisionist definition would offer a "theoretically uniform view over the entire domain of institutionalized games of skill" ([2]: 292).

To conclude this section: Mental stamina enhancement in chess might disqualify chess from being a "sport" (as defined by traditionalists rather than revisionists) ${ }^{15}$ However, it is important to emphasise the distinction between such definitional arguments and ethical objections. If, as suggested in the previous section, ethical objections to safe mental stamina enhancements are dubious, it would seem disproportionate to impose very harsh sanctions on those who breach a rule whose justification rests merely on a definitional argument rather than on ethical considerations. Criminalisation of this type of neurodoping would therefore seem to be contrary to influential criminal law theories, according to which the criminal law should be reserved for seriously immoral conduct (see, e.g., [39]). Even the case for imposing severe non-criminal sanctions for this type of neurodoping seems to be weak in the absence of strong ethical reasons for doing so. WADA seems implicitly to acknowledge this, by basing its rationale for banning doping on moral considerations, rather than on some technical definition of "sport". Therefore, it is concerning that, currently, taking prohibited substances, even if safe, can result in lengthy, even lifelong suspensions and, in some jurisdictions, criminal sanctions. Criminalisation of neurodoping will be the focus of the final part of this article.

\section{The Criminalisation of Neurodoping in Chess}

A number of countries have criminalised doping, including Austria, China and Italy (for an overview see [40]). In the UK, there have been calls to follow suit. The former Prime Minister, David Cameron, wanted this issue debated in parliament and the UK athlete, Paula Ratcliffe has argued that criminalisation of doping would be an effective deterrent ([41]: 225). A Bill was debated in the House of Lords in 2014 which included a clause that would have criminalised doping in sport. ${ }^{16}$ In 2015 , the Minister for Sport, Tracey Crouch stated that "We have to look at criminalisation to see whether or not that's something we can add to the toolbox of combating corruption in sport" [42]. However, ultimately, in 2017, the Department for Culture Media and Sport's Review of Criminalisation of Doping in Sport [43] concluded that a new offence of doping should not be introduced. They noted that aspects of doping (such as possessing or supplying legally prohibited substances) are covered by certain existing offences. ${ }^{17}$ However, athletes are unlikely to face serious criminal penalties in connection with possession of performance enhancing drugs for their own personal use (as opposed to supplying or trafficking them). Possession of certain substances that could be used for neurodoping, such as methylphenidate, without a prescription, is a crime, although it is unlikely that professional chess players would be prosecuted for possessing small quantities without an intent to supply. In theory neurodoping could count as fraud in England and Wales, given the current definition of that crime, ${ }^{18}$

\footnotetext{
${ }^{15}$ There might also be other ways (apart from doping) in which the status of chess as a sport could be undermined. For example, if tournaments were so short or had such frequent breaks that players no longer needed to display endurance, then that type of chess tournament might not count as a sport according to the traditional definition. ${ }^{16}$ Governance of Sport Bill 2014 (HL Bill 20).

${ }^{17}$ Under the Misuse of Drugs Act 1971 and the Medicines Act 1968.

18 The definition of Fraud by false representation is set out in the Fraud Act 2006, S.2 (1), which states that "A person is in breach of this section if he (a) dishonestly makes a false representation, and (b) intends, by making the representation (i) to make a gain for himself or another, or (ii) to cause loss to another or to expose another to a risk of loss." A false representation can be made implicitly - Williams [1980] Crim LR 589. Competitors who knowingly breach anti-doping rules might be considered to make an implied false representation that they have not taken prohibited substances, and if they did so in order to win prize money they could satisfy this definition of fraud.
} 
but the Review of Criminalisation of Doping in Sport found no examples of successful fraud prosecutions of athletes for doping (although in other countries, such as Austria, there have been reported cases of athletes who dope being convicted of fraud) [40]. There are good grounds for welcoming the Review's conclusion that doping should not be treated as a crime (see e.g. [44]). However, the rationale provided for this conclusion in the Review focused on pragmatic considerations - especially difficulties with obtaining enough evidence to secure a conviction. It is worth considering whether there is a principled basis for opposing criminalisation of doping, because sufficient evidence might be available against certain competitors and it might be argued that such individuals should be prosecuted if there were strong principled reasons for doing so. For example, Claire Sumner [41] has argued that the law of fraud should be enforced against athletes who dope (including those taking nonharmful substances), based on the idea that criminalisation of doping is necessary in order to safeguard the spirit of sport. This section will reply to this argument, in the context of the kind of non-harmful neurodoping by chess players discussed in this article, and it will argue that criminalising this kind of non-harmful doping would be disproportionate.

Sumner argues that allowing athletes to take non-harmful substances to enhance their sporting performance could indirectly cause harm. She claims this could be the start of a slippery slope leading to the consumption of more harmful substances ([41]:221). Furthermore, an athlete's personal consumption of drugs could influence the choices of others to consume drugs, especially young, impressionable would-be athletes (a point also made by, e.g., Kaplan [45]:1067; cf. [46,47]). Sumner therefore argues that banning non-harmful performance enhancing drugs is justified on paternalistic grounds. Given the presence of such a ban, doping would be dishonest and would tarnish the reputation of all athletes (even non-dopers) in the eyes of the public. Sumner implies that the public would condemn such conduct as cheating both because it violates the ban and because the public intuitively regard sporting achievements under the influence of drugs to be "super-human" and unnatural ([41]:227). She argues that athletes who violate the ban should be punished both to deter others and on retributive grounds - to give offenders their "just deserts"([41]: 223-224).

Sumner's justification for the ban is partly paternalistic, but her justification for punishing those who violate the ban is partly retributive. There is a tension between these two justifications. The paternalistic rationale denies athletes the right to make autonomous choices about what they do to their own bodies, on the basis that they cannot be trusted to exercise their autonomy wisely, and so the authorities must protect their wellbeing. However, retributivism is based on the idea that offenders are autonomous enough to deserve punishment because of their free choices, and retributivism requires the state intentionally to impose punishments on individuals that typically damage their wellbeing.

In common with WADA, Sumner justifies the ban on non-harmful performance enhancement in order to defend "the spirit of sport" (as characterised by WADA). However, imposing criminal sanctions for breaching this ban seems to go against values comprising the spirit of sport, which motivated the ban in the first place. It is hard to see how the value of "health" could be promoted by imposing criminal sanctions, which have well-known adverse impacts on physical and mental health in response to consuming a substance that is "no more dangerous than caffeine" ([9]:124). (It is even less clear how imposing criminal sanctions in such circumstances would promote the values of "fun and joy".) Nor would it send a clear message promoting the value of health to, on the one hand, criminalise non-harmful performance enhancing substances, while on the other hand, celebrating and financially profiting from sports where competitors, within the rules, intentionally inflict trauma to the head (the unintended consequences of which can include death, permanent brain injury and neurodegenerative diseases). In reply to this kind of argument, Sumner (following Carolan [48]: 25) argues that danger to health does not undermine the spirit of sport when it is "an essential element of the sport" ([41]: 221). If one can prevent (the health aspect of) the spirit of sport from being undermined simply by explaining that causing head injuries is "essential" to a certain sport, it hardly seems that the spirit of sport is so fragile that criminalising non-harmful substances is necessary in order to "defend" it.

There is also uncertainty about how young athletes who take non-harmful performance enhancing substances would be treated on Sumner's approach. Sumner's proposal to criminalise doping is motivated partly by the troubling issue of determining at what age athletes should be allowed to dope 
if doping were not banned. She plausibly suggests such substances should not be used by those under 16 ([41]: 221). However, the troubling issue of determining "a right age" would become even more acute if, as Sumner proposes, non-harmful doping were criminalised. The age of criminal responsibility in England and Wales is $10 .{ }^{19}$ It would go against the aim of protecting children to give them criminal records for taking non-harmful performance enhancing drugs. So, at what age should young people be criminalised for taking such substances if Sumner's proposal were implemented?

Sumner's argument for criminalising doping is based on the "fraud model" and she stresses that "in fraud no harm need be suffered, it is the dishonest conduct which is punished" ([41]: 224). Sumner is right that taking prohibited substances in sport is dishonest and unethical. However, it is only dishonest and unethical, because of the existence of a prior rule banning doping. Furthermore, if this ban is inadequately justified, then, even if the athlete has acted dishonestly, the overall moral case for imposing criminal punishment for the dishonest conduct is weakened. The case for punishing dishonest conduct seems weaker if 1) the (intentional) deception does not (and is not intended to) cause harm, 2) the deceived party does not have a right to demand a truthful answer about a certain issue and 3) demanding a truthful answer could unfairly disadvantage the deceiver. The rule that relatively-easily-fatigued chess players should not consume non-harmful substances to reduce fatigue, and the demand to know whether this rule has been breached might be considered inadequately justified, because 1) the athlete does not intend to cause harm and there is no data supporting the idea that taking such substances indirectly causes others to consume harmful substances, 2) testing for such drugs is arguably too intrusive interfering with individuals' privacy and creating an atmosphere of suspicion and distrust [9], and 3) the ban disadvantages easily fatigued players, compared with competitors, who due to the genetic lottery, are less easily fatigued.

It might even be argued that these three factors do not just weaken the overall moral case for criminalising this kind of doping, but also to some extent diminish the dishonesty of the conduct, although this is more doubtful (see the discussion of moral deceptionism in [49]). An in-depth philosophical discussion of the concept of dishonesty would be required in order to settle that issue, which is outwith the scope of this article. In any case, in circumstances where the above-mentioned three factors are present, the accused does not seem to merit the stigmatic criminal label of "fraudster", which suggests a high degree of dishonesty and seems to imply either that the individual's conduct was harmful or was in some way very culpable (fraud is a crime serious enough to have a maximum sentence of 10 years in prison).

It is also worth noting that the legal definition of fraud requires that the accused's conduct would be considered dishonest according to the standards of ordinary people. ${ }^{20}$ Sumner claims this test would be "easily" met in doping cases and defends criminalisation of doping partly on the basis that the public supposedly considers dopers to be dishonest enough to deserve retributive punishment. However, Kornbeck and Kayser [44] highlight the uncertainty about whether many cases of doping would meet fraud's dishonesty requirement and point out that empirical studies on public attitudes have generated mixed results, with some sectors of the public expressing disapproval and others appearing more tolerant of doping. Kornbeck and Kayser were considering the Ghosh test for dishonesty, which also included the hard-to-prove subjective requirement that the accused realised that the public would view his conduct as dishonest. However, subsequent cases seem to have removed this subjective requirement, making the prosecution's task somewhat easier. ${ }^{21}$ Ultimately, if a fraud prosecution were brought against a competitor for doping, the question of whether ordinary people consider the conduct dishonest would be left to the jury. The conflicting results of different public attitude surveys suggest that if doping were prosecuted, different juries might reach conflicting decisions, potentially creating legal uncertainty and inconsistency.

Demonstrating that "in fraud no harm need be suffered" ([41]: 224) does not show that non-harmful doping should be a crime. Rather, this discussion of fraud and doping arguably highlights the need to

\footnotetext{
${ }^{19}$ Children and Young Persons Act 1933, 50.

${ }^{20} R v$ Ghosh [1982] QB 1053 (CA)

${ }^{21}$ Ivey v Genting Casinos UK Ltd (t/a Crockfords Club) [2017] UKSC 67 and DPP v Patterson [2017] EWHC 2820 (Admin).
} 
reform the current definition of fraud in England and Wales, which has previously been criticised for being too wide [50]. The DCMS argue that doping should not be treated as a crime yet acknowledge that doping can technically count as fraud [43]. They are reassured that prosecutions are unlikely, as it can be hard to prove either that an athlete realised that they were doping, or to prove that doping was done for financial gain. However, Sumner is surely right that there will be some cases where the athlete clearly knew what they were doing and was clearly motivated by the desire to win substantial prize money or sponsorship. The DCMS suggested that the exercise of prosecutorial discretion will prevent doping from being prosecuted as fraud. However, having a definition of fraud that is wide enough to cover doping, combined with heavy reliance on prosecutorial discretion, carries the risk that individuals might be treated inconsistently. If the atmosphere toward doping becomes more punitive, high-profile dopers might be prosecuted to "make an example" of them, while many other competitors who had done the same thing could not be prosecuted, as doping can be hard to detect. It would therefore be beneficial if the definition of fraud in the Fraud Act 2006 were narrower and more precise. The DCMS report suggests that it is generally disproportionate to prosecute doping as fraud, even if harm was caused [43]. Yet, the current definition of fraud is so broad that it could cover the kind of non-harmful doping discussed in this article, which it would be even more disproportionate to prosecute. This provides further reason to reform the definition of fraud.

To summarise: this section has argued that criminalising non-harmful doping in chess would be disproportionate and it should not be prosecuted as fraud.

\section{Conclusion}

This article discussed substances/techniques that target the brain in order to enhance sports performance (known as "neurodoping"). It considered whether neurodoping in mind sports, such as chess, is unethical and whether it should be a crime. Rather than focusing on widely discussed objections against doping based on harm/risk to health, this article focused specifically on the objection that neurodoping, even if safe, would undermine the "spirit of sport". This topic deserves attention, given that a) relatively safe methods of performance enhancement are increasingly being explored in the context of chess; $b$ ) the World Anti-Doping Agency (WADA) currently prohibits performance enhancement if it undermines the spirit of sport, even if it is not dangerous to health; and c) doping (even if safe) seems to fit the current definition of fraud in England and Wales, in certain circumstances, and some academics have argued that non-harmful doping should be prosecuted as fraud.

The article had the following structure. Firstly, it briefly explained why chess can be considered a sport. Secondly, it outlined some possible substances/methods that could be used in order to enhance chess performance and justified the article's focus on one potential form of neurodoping in particular "mental stamina enhancement". Thirdly, this article cast doubt on certain arguments that mental stamina enhancement would be unethical and contrary to the spirit of sport (as defined by WADA). This article stressed the importance of distinguishing the ethical argument that doping violates the "spirit of sport" from the definitional objection that once doping becomes routine in a certain "sport", it would not count as a sport anymore. The fourth section discussed the definitional objection and argued that mental stamina enhancement in chess might disqualify chess from being a "sport" (according to traditional, rather than revisionist definitions of sport). Yet it argued that this definitional objection did not provide strong enough grounds to justify criminalising non-harmful neurodoping. The fifth section of the article responded to a recent proposal to treat doping as a criminal offence and argued that criminalising nonharmful neurodoping would be disproportionate.

\section{References}

1 Franke, A. Gränsmark, A. Agricola, K. Schühle, T. Rommel, A. Sebastian, and Ruckes, C. 2017. Methylphenidate, modafinil, and caffeine for cognitive enhancement in chess: A double-blind, randomised controlled trial. European Neuropsychopharmacology 27 (3): 248-260.

2 Kobiela, F. 2018. Should chess and other mind sports be regarded as sports? Journal of the Philosophy of Sport 45(3): 279-295. 
3 Parkinson, J. 2015. Who, what, why: Do bridge and chess make you fitter? https://www.bbc.co.uk/news/magazine-34323643.

4 Sapolsky, R. 2004. Why Zebras Don’t Get Ulcers. Henry Holt \& Co. pp419-420.

5 Leedy, C. and Dubeck, L. 1971. Physiological changes during tournament chess. Chess Life and Review. 26: 708.

6 Golf, S. 2015. Doping for chess performance. Journal of Sports Medicine and Doping Studies 5(3): 160-176.

7 Alifirov, A. and Mikhaylova, I., 2018. Physical education of highly qualified chess players. Research Journal of Pharmaceutical, Biological and Chemical Sciences 9(4): 1725-1730.

8 Alifirov, A.I., Mikhaylova, I.V. and Makhov, A.S., 2017. Sport-specific diet contribution to mental hygiene of chess player. Theory and Practice of Physical Culture 4: 30-30.

9 Mihailov, E. and Savulescu, J. 2018. Social policy and cognitive enhancement: Lessons from chess. Neuroethics 11: 115-127.

10 FIDE. 2009. Decision of the FIDE Doping Hearing Panel 22/1/09.

https://web.archive.org/web/20090123144930/http://www.fide.com/component/content/article/1-fidenews/3704-decision-of-the-fide-doping-hearing-panel

11 World Anti-Doing Agency. Prohibited List and Monitoring Programme. https://list.wada-ama.org/

12 Fédération Internationale des Échecs. 2018. Chess WADA - Anti-Doping Policy, Nutrition and Health. https://handbook.fide.com/chapter/B12

13 Ragan, C., Bard, I. and Singh, I. 2013. What should we do about student use of cognitive enhancers? An analysis of current evidence. Neuropharmacology. 64: 588-595.

14 Imperatori, L., Milbourn, L. and Garasic, M. 2018. Would the use of safe, cost-effective tDCS tackle rather than cause unfairness in sports? Journal of Cognitive Enhancement 2:377-387

15 Golf, S. 2015. Biochemistry and Psychology of Chess and Classical Physical Exercise: Concurring or Conflicting Evidence? Journal of Sports Medicine and Doping Studies. 5(2): 158-168.

16 Petersen, T. 2020. 'Doping in sport: A Defence. Routledge, chapter 1.

17 World Anti-Doping Agency. 2015. World Anti-Doping Code. https://www.wadaama.org/sites/default/files/resources/files/wada-2015-world-anti-doping-code.pdf.

18 Exner, J. 2018. Anti-doping and athletes' rights under EU law: four-year period of ineligibility as disproportionate sanction? The International Sports Law Journal. 1-11.

19 Geeraets, V. 2018. Ideology, Doping and the Spirit of Sport. Sport, Ethics and Philosophy 12(3): 255-271. 
20 Lippert-Rasmussen, K., \& Petersen, T. 2007. Prohibiting drugs in sports: An enhanced proposal. In Ryberg, J., Petersen, T., Wolf, C. (Eds.) New waves in applied ethics. 237-260. St. Martin's Press.

21 Henne, K., B. Koh, and V. McDermott. 2013. Coherence of drug policy in sports: Illicit inclusions and illegal inconsistencies. Performance Enhancement and Health 2(2): 48-55.

22 Waddington, I., Christiansen, A., Gleaves, J., Hoberman, J., \& Møller, V. 2013. Moving Beyond Responsibility-Shifting, Authenticity, and Cheating Toward a Nature-of-Activities Approach. Recreational drug use and sport: Time for a WADA rethink? Performance Enhancement \& Health 2(2): 41-47.

23 McNamee, M. Transhuman Athletes and Pathological Perfectionism: Recognising Limits in Sports and Human Nature. In Tolleneer, J., Sterckx, S. and Bonte, P. (eds.) Athletic enhancement, human nature and ethics: threats and opportunities of doping technologies. 185-200. Springer.

24 Fischer, J. and Ravizza M. 1998. Responsibility and control: A theory of moral responsibility. Cambridge University Press.

25 Pereboom, D. 2001. Living without Free Will. Cambridge University Press.

26 Maslen, H., Savulescu, J. and Hunt, C. 2020. Praiseworthiness and Motivational Enhancement: 'No Pain, No Praise'? Australasian Journal of Philosophy 98(2): 304-318.

27 Douglas, T. 2014. Enhancing Moral Conformity and Enhancing Moral Worth. Neuroethics 7: 75.

28 Gleaves, J. 2010. No harm, no foul? Justifying bans on safe performance-enhancing drugs Sport, Ethics and Philosophy 4(3): 269-283.

29 Holowchak, M. 2013. Something from nothing or nothing from something? Performanceenhancing drugs, risk, and the natures of contest and of humans. In Tolleneer, J., Sterckx, S. and Bonte, P. (eds.) Athletic enhancement, human nature and ethics: threats and opportunities of doping technologies. 163- 184. Springer.

30 Puddephatt, A. and Fine, G. 2013. Chess as art, science, and sport. In Andrews, D. and Carrington, B. A Companion to Sport. 390-404.

31 Savulescu, J., Foddy, B., Clayton M. 2004. Why we should allow performance enhancing drugs in sport. British Journal of Sports medicine. 666-670.

32 Sandel, M. 2007. The case against perfection. The Belknap Press.

33 Lopez Frias, F. and Devine, J. 2020. 'Philosophy of Sport' in The Stanford Enclycopedia of Philosophy. https://plato.stanford.edu/entries/sport/

34 Magdalinski, T. 2013. Restoring or enhancing athletic bodies: Oscar Pistorius and the threat to pure performance. In Tolleneer, J., Sterckx, S. and Bonte, P. (eds.) Athletic enhancement, human nature and ethics: threats and opportunities of doping technologies. 237-254. Springer.

35 Ter Meulen, R., 2019. Enhancement, hybris, and solidarity: a critical analysis of Sandel's The Case Against Perfection. Medicine, Health Care and Philosophy, 22(3), pp.397-405. 
36 Tännsjö, T. 2019. Caster Semenya, what's next?

http://blog.practicalethics.ox.ac.uk/2019/05/caster-semenya-whats-next/

37 Parry, J. 2018. E-sports are Not Sports. Sport, Ethics and Philosophy. 13(1): 1-18.

38 Suits, B. 2007. The Elements of Sport. In Morgan, W. Ethics in Sport. 9-19. Human Kinetics.

39 Duff R. 2001. Punishment, Communication and Community. Oxford University Press 2001.

40 Murphy, J. 2013. Where in the world is doping a crime? (doping in sports pt. 6).

http://www.aph.gov.au/About_Parliament/Parliamentary_Departments/Parliamentary_Library/Flag

Post/2013/April/Where_in_the_world_is_doping_a_crime_doping_in_sports_pt_6.

41 Sumner, C. 2017. The spirit of sport: The case of criminalisation of doping in the UK. The International Sports Law Journal. 16: 217-227.

42 Kelso, P. 2015. Doping May Be Made A Crime In New Sport Strategy.

https://news.sky.com/story/doping-may-be-made-a-crime-in-new-sport-strategy-10335726

43 HM Government. Department for Culture, Media and Sport. 2017. Review of Criminalisation of Doping in Sport.

https://www.gov.uk/government/uploads/system/uploads/attachment_data/file/654240/Review_of_Cri minalisation_of_Doping_in_Sport.pdf.

44 Kornbeck, J. and Kayser, B. 2018. Do public perception and the 'spirit of sport' justify the criminalisation of doping? A reply to Claire Sumner. The International Sports Law Journal. 18:6178.

45 Kaplan, J. 1971. The role of the law in drug control. Duke Law Journal. 1065-1068.

46 Petersen, T. (2010). Good athlete-bad athlete? On the 'role-model argument' for banning performance-enhancing drugs. Sport, Ethics and Philosophy. 4(3): 332-340

47 Veber, M. (2014). The coercion argument against performance-enhancing drugs. Journal of the Philosophy of Sport. 41(2): 267-277

48 Carolan, E. 2006. The new WADA code and the search for a policy justification for anti-doping rules. Seton Hall Journal of Sports and Entertainment Law. 16(1): 1-43.

49 Mahon, J. 2015. The Definition of Lying and Deception. The Stanford Encyclopedia of Philosophy. https://plato.stanford.edu/entries/lying-definition/\#MorDec

50 Ormerod, D. 2007. The Fraud Act 2006 - Criminalising lying? Criminal Law Review. 193: 196204. 